\title{
Depth Profiles of Lanthanide Tetrad Effect in the Western Indian Ocean and their Implications
}

\author{
By Akimasa MASUDA ${ }^{+)}$and Junji SHIMODA \\ Department of Chemistry, University of Electro-Communications, Chofu, Tokyo 182 \\ (Communicated by Kazuo Yamasaki, M. J. A., Nov. 12, 1997)
}

\begin{abstract}
The depth profiles for degree of the lanthanide tetrad effect are presented for three seawater columns from an area in the western Indian Ocean off Madagascar. The features of the depth profiles for the upper layer of this area show a developed local variation. With the exception of this locality, the profiles as a whole exhibit the middle-valley patterns, in common with those in the North Pacific. The depth corresponding to the middle valley and the maximum value for the lanthanide tetrad effect observed in the column have been estimated for the first time from the curve drawn for the lanthanide tetrad effect profile. A comparison is made between Indian and North Pacific Oceans. There are clear differences between these two oceans in both the water depth of the middle valley and the maximum aberration due to the tetrad effect observed in the column. These characteristics are consistent with a picture presented thus far by oceanography researchers. That is, the difference between the two oceans is considered to reflect a distinction between southern hemisphere and northern hemisphere.
\end{abstract}

Key words : Lanthanide tetrad effect; depth profile; REE; n-ABEXEL; lanthanides; seawater; Indian Ocean; Pacific Ocean; ocean; water mass.

Since the first report ${ }^{1)}$ announcing the discovery of the lanthanide tetrad effect in seawater, this effect has drawn considerable interest in many places. In particular, however, some geochemists ${ }^{2}$ have extensively criticized this phenomenon, claiming that it may be attributed to either experimental errors or merely an artifact. Low quality data underlie the misleading arguments.

To convince the suspicious geochemists of the common occurrence of this effect in our environments, two ways would be valid. One is to evince a physico-chemical background ${ }^{3)-5)}$ accountable for the phenomenon under consideration. Another is to show the high utility or broad significance of this effect in earth sciences. Whereas this phenomenon was first found out in seawater, ${ }^{1)}$ to explore its utility in oceanography would be one of the shortest approaches to the goal. With this aim in mind, we have started to study the depth profiles of the lanthanide tetrad effect in seawater columns based on high precision data.

The study first published by us ${ }^{6)}$ concerning the depth profile is for two water columns of the North West Pacific Ocean, which were precisely analyzed by Piepgras and

†) Correspondence should be addressed to: 449 Shimo-Yasumatsu, Tokorozawa, Saitama 359, Japan.
Jacobsen $^{7)}$ for rare-earth elements (REE). We were able to obtain interesting smooth patterns for depth profiles. These patterns have been discussed in relation with available physical and chemical data. ${ }^{12)}$ Of the chemical parameters, the dissolved oxygen appears to be related most closely with the pattern of the depth profile for the tetrad effect.

ABEXEL profile for the western Indian Ocean. In this communication, we report the results for western Indian Ocean and its adjacent seas which were studied by Bertram and Elderfield ${ }^{8)}$ Locations of water columns are indicated on their map ${ }^{8)}$ (Fig. 1). Although they reported large data, good-quality data suitable for our mathematical analysis ${ }^{9)}$ are limited in number. To evaluate the degree of the lanthanide tetrad effect for light REE, high precision data are required at least for $\mathrm{La}, \mathrm{Nd}, \mathrm{Sm}$ and $\mathrm{Gd}$. We screened the data not only based on four elements concerned but also on other REE analyzed by the original authors. A criterion of "good-quality data set" in dealing with the Bertram and Elderfield data was that three significant figures are described for all of $\mathrm{La}, \mathrm{Ce}, \mathrm{Nd}, \mathrm{Sm}$, $\mathrm{Eu}, \mathrm{Gd}, \mathrm{Dy}, \mathrm{Er}, \mathrm{Yb}$ and Lu which can be determined by isotope dilution method. However, for Lu we have chosen cases where two significant figures are described, for our 




Fig. 1. The locations of water columns studied (after Bertram and Elderfield ${ }^{8)}$ ) for the western Indian Ocean.

mathematical analysis for the lanthanide tetrad effect when their uncertainties have been judged to be nearly $1 \%$. In this communication, our attention is directed to the effect for light REE, which is evaluated as "ABEXEL" value. ${ }^{6), 9)}$ Although details of mathematical treatment are omitted here, $\mathrm{ABEX}$ is defined to indicate quantitatively the extent of fractionation within the lanthanide tetrad group. A value designated as ABEXEL is the ABEX value for two light tetrads covering La through Gd. Lanthanide abundances in the Leedey chondrite ${ }^{13)}$ were used for normalization.

After sorting the data in the way described above, we calculated the ABEXEL values and plotted them against the depths for three stations, 1502, 1504 and 1507. In Fig. 2 the depth profiles for 1502 (crosses) and 1504 (solid circles) are shown. Fig. 3 shows the depth profile for 1507 (solid circles). The curves were drawn mainly using the "3D spline program of Kaleida Graph"; "smooth program" was also tried for the uppermost part of the column. Gross common feature for the three profiles is the occurrence of the U- or V-shaped middle-valley pattern exhibited in the profiles. Similar features have been observed in the profiles $^{6)}$ for the North West Pacific Ocean (Fig. 4). Needless to say, the position for the bottom of the middle

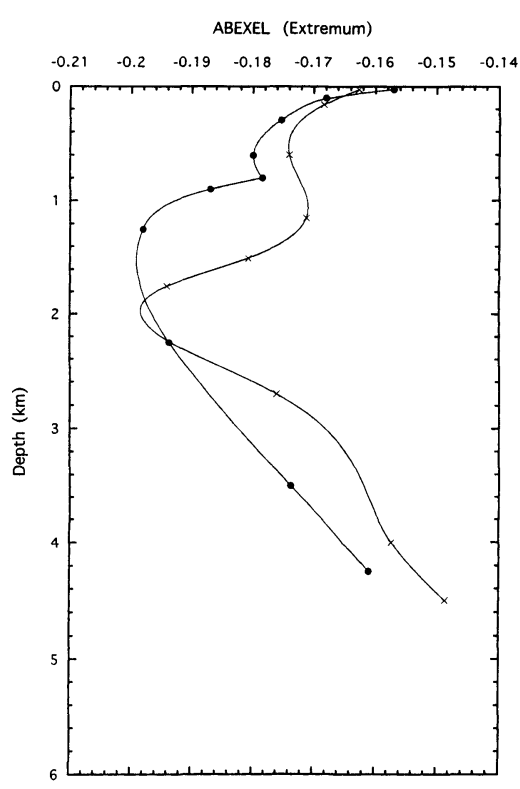

Fig. 2. Depth profiles of ABEXEL at locations 1502 (crosses) and 1504 (solid circles).

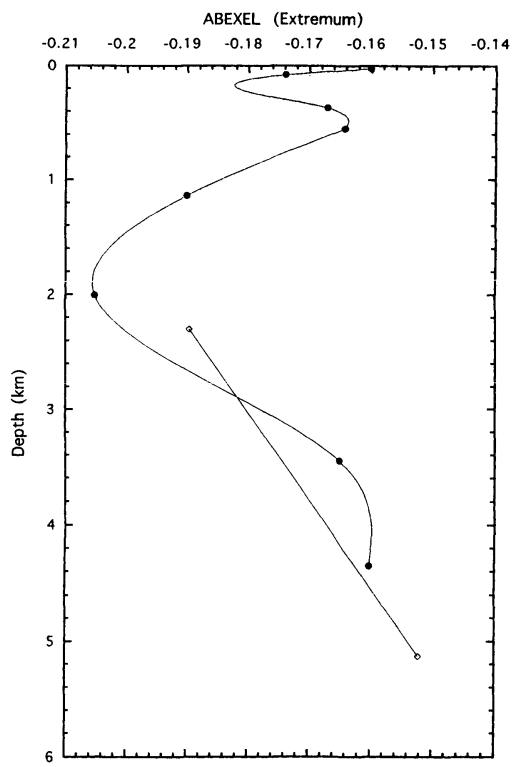

Fig. 3. Depth profiles of ABEXEL at location 1507 (solid circles). Symbol of diamond refers to location 1506.

valley corresponds to the maximum of negative ABEXEL (n-ABEXEL).

So far as the available profiles are concerned, the curves for the layer deeper than the middle valley bottom are relatively smooth and simple. However, the curve for the upper layer shallower than the middle valley bottom has features variable from location to location. The depth profile for upper layer of location 1502 has a broad saddle, 


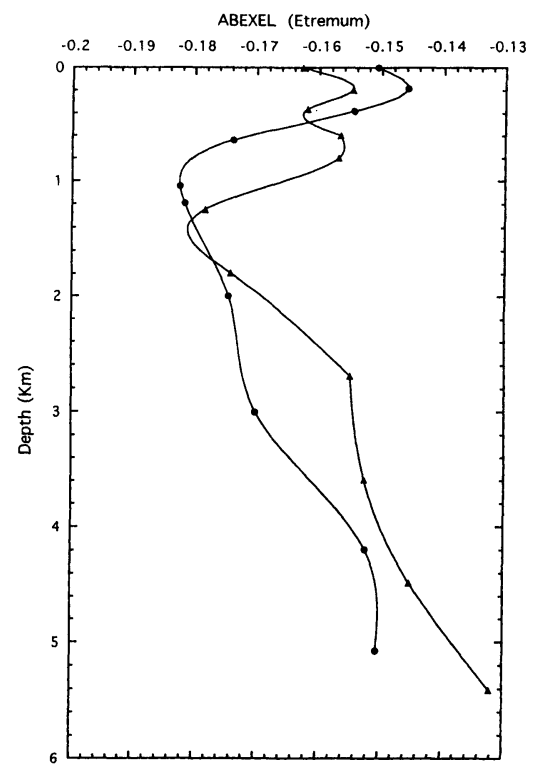

Fig. 4. Depth profiles of ABEXEL at two locations ${ }^{7)}$ in the North West Pacific. Symbol marks, solid triangles and solid circles, refer to locations $39-1$ and $271-1$, respectively. The latitudes of locations are cited in Table $\mathrm{I}$.

while that for location 1504 shows a narrow saddle. Meanwhile, the upper layer profile for location 1507 appears to exhibit a small valley. In view of the fact that the number of the points concerned is quite limited, it may be premature to draw any conclusions about the features of the uppermost layer at location 1507. However, it is interesting that each of the three columns studied here was collected from a different basin (Fig. 1).

At any rate, the western Indian Ocean seawaters have developed a marked locality characterized by the upper-layer depth profiles. This locality developed in the upper layer around Madagascar can reflect the complicated surface currents at the area investigated and the difference in submarine topographical conditions. For purposes of comparison, it is worthwhile to note that the upper-layer profile for the sub-tropical location (271-1) of the western North Pacific is the simplest among the sites examined for ABEXEL depth profile. It is noted here that the Indian Ocean is situated in the southern hemisphere. These facts are consistent with the oceanographic picture cited in Fig. 5 , where relatively complicated environments are generally indicated for the upper layer of the seawaters in the southern hemisphere.

If upwelling takes place, the features for the upper layer should be sensitive to it. The saddle-like structure may have something to do with the upwelling activity. Those for the deep layer can reflect the submarine topography and the direction of flow of water mass. In this connection, a rather unique topography for location 1502 and a unique profile for it draw our attention. This site is located near a neck between Mascarene and Somali Basins.

ABEXEL values for adjacent seas. The ABEXEL values available for Arabian Sea and Gulf of Oman are confined to the uppermost layers (Fig. 6), except one point for the Arabian Sea. We observe that the ABEXEL value varies covering a wide range (from -0.11 to -0.17 ) in the uppermost layer, and that the n-ABEXEL values can be notably low as compared with those for the surface waters of oceans. The low absolute values of ABEXEL mean less intra-tetrad fractionation and indicate the water mass being young. The ABEXEL values for typical igneous rocks of the earth's crust are substantially zero.

Comparison with the North Pacific. Already in the foregoing paragraphs, some comparison has been made between the Indian and Pacific Oceans. Here our major attention will be focussed on the water depth corresponding to n-ABEXEL maximum and the value of the $n$ ABEXEL maximum itself. The relevant data are summarized in Table I. It can be seen that the n-ABEXEL maximum depth is greater in Indian Ocean than in the North Pacific. Note a fact that the salinity minimum layer $\left(\mathrm{S}_{\min }\right)$ is deeper in the southern hemisphere than in the northern hemisphere (Fig. $5^{10)}$ ). Apart from the distinction between the western Indian Ocean and North West Pacific Ocean, Table I reveals that the depth for $n$-ABEXEL maximum ranges from 1 to $2 \mathrm{~km}$. This depth range coincides with the depths of boundaries ${ }^{10)}$ between AIW and PDW and between AAIW and PDW (Fig. 5) Shallower depth for n-ABEXEL maximum depth can indicate in general the greater thickness of deep layer in open ocean.

As given in Table I, the n-ABEXEL maxima for three columns in Indian Ocean investigated are 0.199-0.205, while those for two columns of North Pacific Ocean are $0.181-0.182$. There is a definite difference in n-ABEXEL maximum value between the Indian and the North Pacific Ocean. It merits attention that the locations of two water columns for the North Pacific vary widely in latitude. Dietrich et al. ${ }^{10)}$ have illustrated (Fig. 5) that there is a distinction in circulation between the North Pacific and the South Pacific. Meanwhile locality is also observed for the breadth of the "middle valley" in spite of the high similarity of the maximum of n-ABEXEL for three columns at locations 1502, 1504 and 1507. This suggests the movement of the deep-layer water masses and/or the differentiation of sinking rates of particulates.

Occurrence of n-ABEXEL maximum in the seawater column would be explained in terms of supplies of primary 


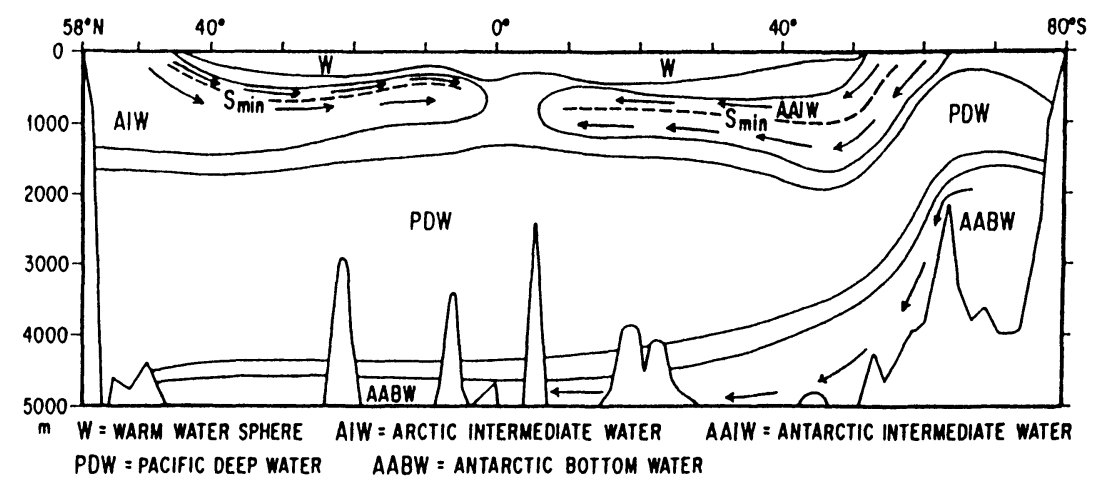

Fig. 5. Cross section of the Pacific Ocean at $160^{\circ} \mathrm{W}$ showing the major water masses and their direction of flow (after Dietrich et al. ${ }^{10)}$ ).

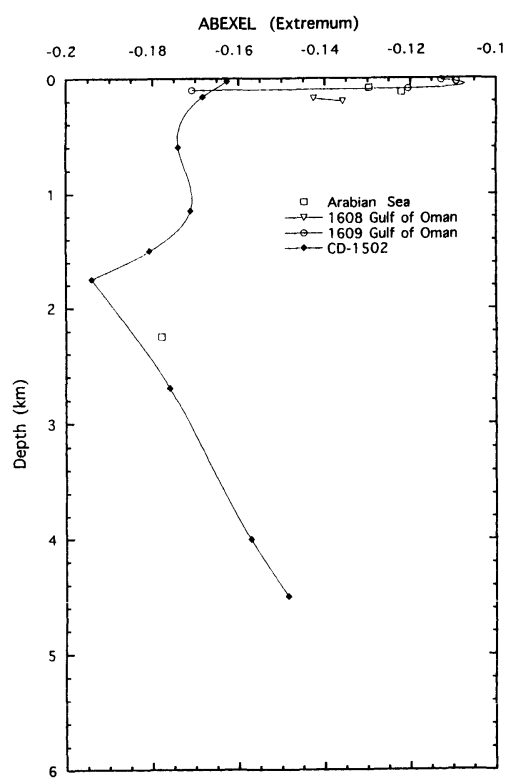

Fig. 6. ABEXEL values (open symbols) for Arabian Sea and Gulf of Oman ${ }^{8)}$ (see Fig. 1). A solid curve shows the ABEXEL level at location 1502 in Indian Ocean.

terrigenic dust or particulates from the atmosphere and from the bottom of ocean and the temporary stabilization of simple lanthanide cations $\left(\mathrm{Ln}^{3+}\right)$. The simple "free" $\mathrm{Ln}^{3+}$ ions can be liberated in the chemical change ${ }^{11)}$ of the sinking primary dust or particulates to the secondary marine ones as represented by hydroxides of most of major elements and marine clayey minerals. It is difficult to discuss quantitatively the kinetic effect and the effect of equilibrium. Qualitatively, the kinetic effect would be tangible in the marine environments.

From a simple viewpoint of the mass balance, it is natural that the absolute values of n-ABEXEL are low at the top and at the bottom of the water column. It follows that the values at the top would be nearly the same as
Table I. Depth and value for n-ABEXEL maximum

\begin{tabular}{lrccc}
\hline Ocean & Loc. no. & $\begin{array}{c}\text { n-ABEXEL } \\
\text { max. depth }\end{array}$ & $\begin{array}{c}\text { n-ABEXEL } \\
\text { maximum }\end{array}$ & Latitude \\
\hline Indian & 1504 & $1.52 \mathrm{~km}$ & 0.199 & $27^{\circ} 00^{\prime} \mathrm{S}$ \\
& 1502 & $2.00 \mathrm{~km}$ & 0.1985 & $12^{\circ} 18^{\prime} \mathrm{S}$ \\
& 1507 & $1.88 \mathrm{~km}$ & 0.2055 & $06^{\circ} 09^{\prime} \mathrm{S}$ \\
N. Pacific & $271-1$ & $1.00 \mathrm{~km}$ & 0.182 & $24^{\circ} 17^{\prime} \mathrm{N}$ \\
& $39-1$ & $1.40 \mathrm{~km}$ & 0.181 & $47^{\circ} 00^{\prime} \mathrm{N}$ \\
& & & & \\
\hline
\end{tabular}

those at the bottom in the steady state which can be roughly simulated by a closed vertical column.

The absolute values of n-ABEXEL can be enhanced in between the top and the bottom layer owing to the halfway increase of the contribution of simple $\mathrm{Ln}^{3+}$ ions. The stabilization of $\mathrm{Ln}^{3+}$ ions would be realized through the formation of complexes with inorganic and organic anions and/or through adsorption of the hydrated simple lanthanide ion $\mathrm{Ln}^{3+}$ onto the surface of inorganic or organic particulates. An apparently close correlation ${ }^{6), 12)}$ of ABEXEL value with dissolved oxygen can be interpreted to suggest the greater roles of organic anions and organic particulates. In this sense, it is likely that biogenic organic components play an important part in affecting the distribution of lanthanides marked with the tetrad effect, because considerable fractions of organic materials, derived from the biological activity and from the remains of marine life, can be materials or compounds having phosphate group as a functional one which is active in formation of chemical bonding with $\mathrm{Ln}^{3+}$.

The results presented here demonstrate that the lanthanide tetrad effect can serve as a potential new tool which cannot be replaced by such conventional tools as isotopes, elemental concentrations and concentration ratios of elements. The lanthanide tetrad effect can potentially act as an oceanographic marker comparable 
with temperature, salinity and dissolved oxygen and shed a new light into seawater studies of watermasses, specifically, of their origin and movement. At the same time, emphasis should be placed here that a high precision data ( $1 \%$ or better) is required for REE to play such a role.

Acknowledgements. We thank Prof. I. Kawabe, Nagoya University, for his comments.

\section{References}

1) Masuda, A., and Ikeuchi, Y. (1979) Geochem. J. 13, 19-22.

2) McLennan, S. M. (1994) Geochim. Cosmochim. Acta 58, 2025-2033.

3) Jørgensen, C. K. (1979) In Handbook on the Physics and Chemistry of Rare Earths (eds. Gschneider, K. A., Jr., and Eyring, L.). North-Holland, Amsterdam, vol. 3, pp. 111-169.

4) Kawabe, I. (1992) Geochem. J. 26, 309-335.

5) Masuda, A. (1995) Proc. Japan Acad. 71B, 165-169.
6) Masuda, A., and Shimoda, J. (1996) Proc. Japan Acad. 72B 202-207.

7) Piepgras, D. J., and Jacobsen, S. B. (1992) Geochim. Cosmochim. Acta 56, 1851-1862.

8) Bertram, C. J., and Elderfield, H. (1993) Geochim. Cosmochim. Acta 57, 1957-1986.

9) Masuda, A., Matsuda, N., Minami, M., and Yamamoto, H. (1994) Proc. Japan Acad. 70B, 169-174.

10) Dietrich, G., Kalle, K., Kraus, W., and Siedler, G. (1980) General Oceanography: An Introduction. J. Wiley \& Sons, p. 626 .

11) Sholkovitz, E. R., Landing, W. M., and Lewis, B. L. (1994) Geochim. Cosmochim. Acta 58, 1567-1579.

12) Masuda, A., and Shimoda, J. (1997) Proc. Japan Acad. 73B, 39-43.

13) Masuda, A., Nakamura, N., and Tanaka, T. (1973) Geochim. Cosmochim. Acta 37, 239-248. 